\title{
Cardiac transplant or rotary blood pump: Contemporary evidence
}

\author{
Stephen Westaby, MS, PhD, FRCS, FECTS, FESC, FACC
}

Congestive heart failure affects 23 million people worldwide including 7.5 million in North America $(670,000$ new cases per year) and 7 million in Europe. ${ }^{1}$ Inasmuch as systolic left ventricular dysfunction develops in $10 \%$ of the population over 65 years, the number of patients with heart failure will double during the next 2 decades. At any time, $10 \%$ of patients are categorized as having stage D disease-advanced structural heart disease and symptoms at rest, despite detailed medical and cardiac resynchronization therapy. Twenty percent are younger than 65 years of age, comprising between 100,000 to 150,000 patients for both the United States and Europe. ${ }^{2}$

The population with chronic preterminal heart failure has short wretched lives. In the Randomized Evaluation of Mechanical Assistance for the Treatment of Congestive Heart Failure (REMATCH) study, only $8 \%$ of the medically treated patients were alive at 2 years and remained housebound with severe breathlessness and fatigue in the interim. ${ }^{3}$ A recurrent sentiment is that they would sacrifice some duration of survival for periods of symptomatic relief. ${ }^{4}$ With the cardiologist as gatekeeper, cardiac resynchronization therapy is widely used at substantial cost but cannot be regarded as effective in severely debilitated patients (Figure 1). A meta-analysis of 14 trials that randomized resynchronization against medical treatment showed only $59 \%$ of the patients in New York Heart Association (NYHA) class IV supported with a device to have borderline symptomatic improvement to NHYA class III with no survival benefit..$^{5}$ Boyle and associates ${ }^{6}$ compared functional outcomes for patients in NYHA class IV after resynchronization or implantation of a pulsatile left ventricular assist device (LVAD). By 6 months, resynchronized patients achieved only an additional $6 \mathrm{~m}$ in the 6-minute walk test and remained in NHYA class III/IV. In contrast, patients with an LVAD improved by $341 \mathrm{~m}$, achieving NYHA class I or II. Notably, the study could not be randomized because $90 \%$ of LVAD candidates were bedbound on intravenous inotropes and were unable to walk beforehand. Thus the

From Oxford University Hospitals, Oxford, and Institute of Life Sciences, University of Swansea, United Kingdom.

Disclosures: Author has nothing to disclose with regard to commercial support.

Received for publication May 21, 2012; revisions received July 23, 2012; accepted for publication Aug 21, 2012.

Address for reprints: Stephen Westaby, MS, PhD, FRCS, FECTS, FESC, FACC, Oxford Heart Center, John Radcliffe Hospital, Department of Cardiothoracic Surgery, Headley Way, Headington, Oxford, Oxfordshire OX3 9DU, United Kingdom (E-mail: Stephen.Westaby@orh.nhs.uk).

J Thorac Cardiovasc Surg 2013;145:24-31

$0022-5223 / \$ 36.00$

Copyright $(c) 2013$ by The American Association for Thoracic Surgery

http://dx.doi.org/10.1016/j.jtcvs.2012.08.048 potential options for those who exhaust maximum medical therapy are palliative care, a lifetime LVAD, or cardiac transplantation. Even in affluent health care systems the vast majority receive only palliative care irrespective of age. ${ }^{7}$

Cardiac transplantation is repeatedly described as the gold standard treatment for severe heart failure. In epidemiologic terms, this is similar to describing a lottery win as the preferred method to gain wealth. On a more optimistic note, recent data from the Fourth INTERMACs Annual Report demonstrate 1- and 2-year rotary LVAD survivals of $80 \%$ and $70 \%$ in predominantly non-transplant-eligible patients. ${ }^{8}$ Particularly favorable survival of $85 \%$ at 2 years was recorded for patients up to 70 years without diabetes, renal impairment, or cardiogenic shock. This considerable achievement is placed into context by the much less satisfactory $56 \%$ and $33 \%$ survivals with the pulsatile HeartMate XVE device (Thoratec Corporation, Pleasanton, Calif) only 5 years before. ${ }^{9}$ With improvements in technology, the survival curves for transplantation and mechanical circulatory support are converging. Carefully selected and electively implanted patients can anticipate 5 years of event-free survival as far as out to 7.5 years. ${ }^{10-12}$ This situation now calls for prospective randomized trials of cardiac transplantation versus mechanical circulatory support in specific patient groups. ${ }^{13}$ In the meantime, the aim of this review is to rationalize the evidence base and indications for these complementary therapies.

\section{WHAT DO WE KNOW ABOUT CARDIAC TRANSPLANTATION?}

Essentially restricted to patients less than 65 years without significant comorbidity, fewer than 2200 donor hearts per year are made available in the United States and around 100 in the United Kingdom. The early experience at Stanford University Medical Center between January 1968 and August 1976 demonstrated overall 1- and 2-year survivals of $52 \%$ and $43 \%$, together with a $90 \%$ return to NYHA class I. ${ }^{14}$ In this era, $95 \%$ of patients selected but not receiving a transplant died within 6 months of evaluation. Because of these original observations, transplantation has never been tested against alternative treatments in a prospective randomized model. During the past 20 years, substantially improved outcomes have been achieved with drugs and nontransplant heart failure surgery. ${ }^{15}$ This has reduced the comparative survival benefit gained by transplantation in some categories of patient. 


\section{Abbreviations and Acronyms \\ COMPANION $=$ Comparison of Medical \\ Therapy, Pacing, and \\ Defibrillation in Heart \\ Failure (Investigators) \\ COPERNICUS $=$ Carvedilol Prospective \\ Randomized Cumulative \\ Survival (Study Group) \\ CUBS $=$ Clinical Utility Baseline \\ Study (Group) \\ ESSENTIAL $=$ Studies of Oral Enoximone \\ Therapy in Advanced Heart \\ Failure (Trial) \\ INTERMACS $=$ Interagency Registry for \\ Mechanically Assisted \\ Circulatory Support \\ INTrEPID = Investigation of \\ Nontransplant-Eligible \\ Patients Who Are Inotrope \\ Dependent (trial) \\ LVAD = left ventricular assist device \\ NYHA $\quad=$ New York Heart Association \\ REMATCH $=$ Randomized Evaluation of \\ Mechanical Assistance for \\ the Treatment of Congestive \\ Heart Failure \\ REVIVE-IT $=$ Randomized Evaluation of \\ VAD Intervention before \\ Inotropic Therapy (study) \\ UNOS $\quad=$ United Network for Organ \\ Sharing}

Currently the median posttransplant longevity is 12.2 years with a 1-year survival of around $85 \% .{ }^{16}$ However, there are twice as many patients listed for transplantation annually as there are donor hearts and approximately $8 \%$ die while waiting. Equally, more than $20 \%$ of those receiving transplants die within 3 years. ${ }^{17}$ Data from the United Network for Organ Sharing (UNOS) currently suggest benefit for hospitalized patients on inotropic and intra-aortic balloon pump or LVAD support (UNOS status I) but question the value of transplantation for ambulatory patients whose condition has yet to deteriorate into critically low cardiac output (UNOS status II). ${ }^{18}$ At $89 \%$, the 1 -year survival of status II candidates who have not had surgery is equivalent to or exceeds the outcome of transplantation. In $2005,48 \%$ of heart transplant candidates had spent more than 2 years on the waiting list and survival of status I patients approached $70 \% .{ }^{19}$ These data echo the findings of Deng and coworkers, ${ }^{20}$ who showed that status II wait-listed patients who did not receive a donor heart had
3- and 4-year survivals similar to those of patients receiving a transplant. Around $30 \%$ of status II patients improve symptomatically and prognostically when managed by a specialist heart failure team. Patients are then considered too well for transplantation if they demonstrate a sustained improvement in peak oxygen uptake of more than $2 \mathrm{~mL}$. $\mathrm{kg}^{-1} \cdot \min ^{-1}$. Furthermore, Shah and colleagues ${ }^{21}$ showed that 1- and 3-year survivals for status II patients removed from the waiting list were $100 \%$ and $92 \%$, respectively. Idiopathic dilated cardiomyopathy, the most frequent diagnosis in transplant patients, often showed spontaneous improvement and better prognosis than ischemic cardiomyopathy. In addition, some patients with idiopathic dilated cardiomyopathy respond to mechanical ventricular unloading with reverse remodeling and sustained improvement in left ventricular function. ${ }^{22}$

For status I candidates, predictors of early death (within 2 months) are the need for mechanical ventilation, valvular cardiomyopathy, UNOS status Ia, serum creatinine greater than $1.5 \mathrm{mg} / \mathrm{dL}$, presence of an intra-aortic balloon pump, age greater than 60 years, use of intravenous inotropic drugs, body weight less than $70 \mathrm{~kg}$, and pulmonary capillary wedge pressure less than $20 \mathrm{~mm} \mathrm{Hg} .{ }^{23}$ Without treatment, these patients have a projected mortality varying from imminent to more than $50 \%$ at 6 months, whereas transplant survival exceeds $80 \%$ at 1 year and is almost $50 \%$ at 10 years. Eligibility for transplantation remains dependent on age and comorbidity with direct sequelae of chronic heart failure (pulmonary hypertension and renal impairment) mitigating against suitability. ${ }^{24}$

In the absence of randomized trials, recent comprehensive registry data from UNOS help to define who should and should not receive a transplant. In an analysis of 22,385 patients undergoing transplantation, Kilic and associates $^{25}$ found that $42 \%$ survived for 10 years or more, but for those who did not reach 10 years, mean survival was $3.7 \pm 3.3$ years. Clear predictors of transplant longevity were age less than 55 years, white race, younger donor age, and shorter donor heart ischemic time. Diabetes, renal impairment, and the need for preoperative ventilation militated against long-term survival. In a separate report, the same authors reviewed data from 15,960 patients who had received transplants (1998-2008), observing the influence of metabolic risk factors on survival. ${ }^{26}$ Preoperative hypertension was found in $40 \%$ of patients, obesity in $25 \%$, and diabetes in $21 \%$. Only $40 \%$ had none of the 3 , whereas $18 \%$ had 2 and $4 \%$ had all 3 risk factors. Those with all 3 were older (mean age, 55 vs 50 years), more likely to be male, and had significantly higher serum creatinine levels. They were more likely to have ischemic than idiopathic dilated cardiomyopathy and to receive an LVAD $(20 \%)$ as bridge to transplantation. From multivariate analysis incorporating 22 covariates, each of the 3 factors was found to be a significant predictor for reduced survival. 


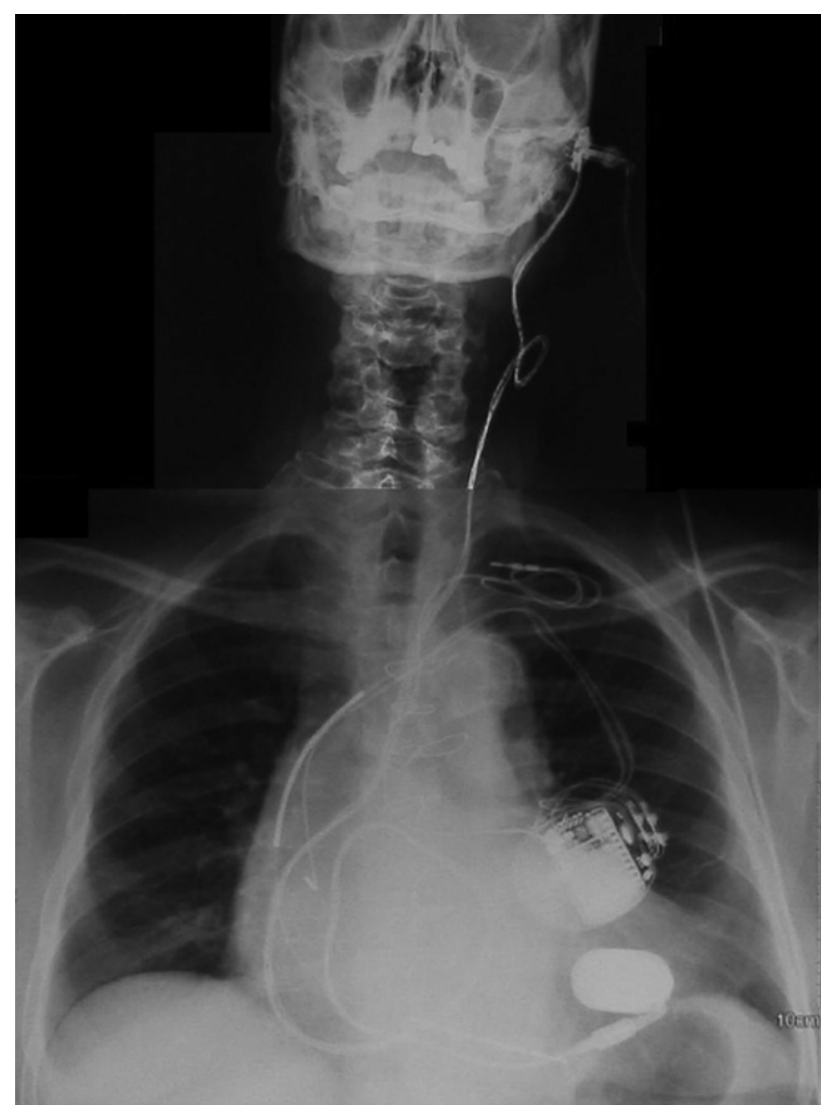

FIGURE 1. Myocardial regeneration therapy. Plain radiograph of a patient with ischemic cardiomyopathy with cardiac resynchronization and an implantable defibrillator who was inotrope dependent in the hospital for 3 months. He received a Jarvik FlowMaker device with a skull pedestal power delivery plus intramyocardial injection of autologous bone marrow stem cells. Twelve months later he was in New York Heart Association class I with objective evidence of improved myocardial perfusion and contractility. (From Anastasiadis K, Antonitsis P, Doumas K, Koliakos G, Argiriadou $\mathrm{H}$, Vaitsopolou $\mathrm{C}$, et al. Stem cells transplantation combined with long-term mechanical circulatory support enhances myocardial viability in end-stage ischemic cardiomyopathy. Int J Cardiol. 2012;155:e51-3. Reprinted with permission from Elsevier.)

Diabetes independently increased the odds of mortality by $22 \%$, obesity by $17 \%$, and hypertension by $10 \%$ (each $P$ $<.01)$. When patients with all 3 risk factors were compared with those with none, the increased mortality risk was $63 \%$. Thus the adverse impact was exponentially greater when diabetes, obesity, and hypertension were present in combination. Kilic's study suggested a higher mortality risk for those with a body mass index greater than $30 \mathrm{~kg} / \mathrm{m}^{2} .^{26}$ In the meantime, a recent UNOS analysis suggested that a body mass index between 30.0 and $34.9 \mathrm{~kg} / \mathrm{m}^{2}$ did not increase mortality but that patients with a body mass index greater than $35 \mathrm{~kg} / \mathrm{m}^{2}$ had worse survival. ${ }^{27}$ These data support the findings of Lietz and colleagues ${ }^{28}$ that both cachectic and obese patients are subject to poor early posttransplant outcomes.

\section{IMPROVING TRANSPLANT SELECTION CRITERIA ON THE BASIS OF CURRENT EVIDENCE}

In the absence of prospective randomized trial data, the transplant registries in comparison with clinical trials of medical therapy provide the best comparative evidence base. In the United States, approximately $75 \%$ of heart transplantations are now performed in UNOS status I patients. Figures 2 and 3 depict the effect of medical treatment from major trials in patients in the UNOS waiting list for heart transplantation stratified as status Ia, Ib, and II. On the basis of these observations, transplantation may not provide benefit to patients deemed status Ib or II. ${ }^{29}$ Patients whose condition can be improved by beta-blockers or resynchronization/defibrillator therapy (COPERNICUS and COMPANION type of patients) will probably not derive benefit from transplantation. ${ }^{30,31}$ Patients in the UNOS $1 \mathrm{~b}$ category may remain stable and retain benefit from medical treatment or will progress to refractory terminal heart failure. Patients with the most advanced forms (ESSENTIAL and REMATCH) have the greatest risk of mortality when compared with those who receive a transplant and are likely to derive benefit. ${ }^{3,32}$ Accordingly, potential transplant benefit should be assessed against the predicted outcome after recompensation and implementation of optimal medical management.

In summary, registry data indicate the best survival advantage for UNOS status Ia patients younger than 55 years of white race without metabolic risk factors, who benefit from a donor heart less than 40 years of age with short ischemic time. It could be argued that scarce donor hearts should be allocated only to patients with projected longterm survival. Cardiac transplantation remains necessary for young patients with palliated complex congenital heart disease or dilated cardiomyopathy with poor right ventricular function. Together, these could account for all available donor hearts. This raises the question as to whether older patients with ischemia and metabolic risk factors should be considered. In practice, this route seems harsh and morally questionable unless alternative treatment is available.

\section{IS A LIFETIME LVAD A REALISTIC ALTERNATIVE TO TRANSPLANTATION}

The pulsatile LVAD was designed to replicate the failing left ventricle; thus its size was determined by the need to produce stroke volume at similar pulse rates to the native heart. Over the past 10 years, pump technology has changed markedly with the revelation that pulse pressure is not a fundamental requirement in the human circulation. ${ }^{33}$ It is also clear that modest increases in blood flow 


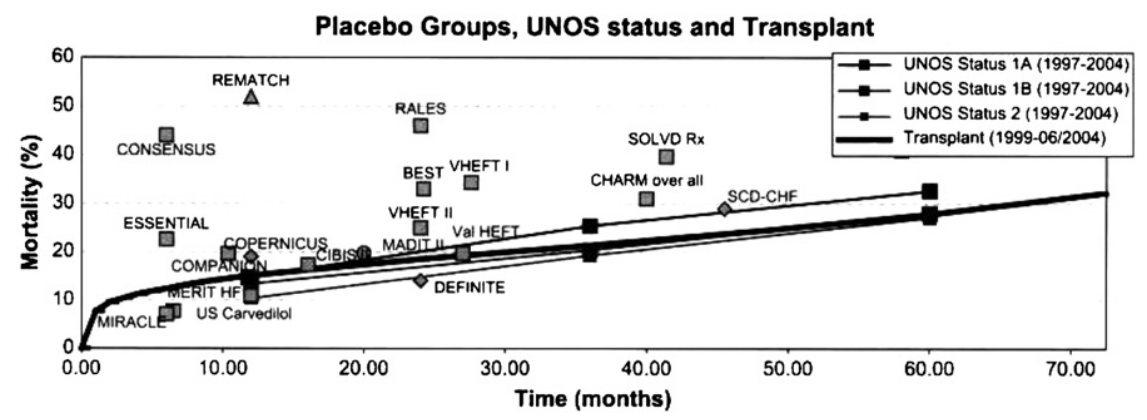

FIGURE 2. General comparative analysis of outcomes of patients listed for heart transplantation as status 1A, 1B, and 2, patients undergoing orthotopic heart transplantation, and patients in the placebo groups reported by major clinical trials. OPTN, Organ Procurement and Transplantation Network; UNOS, United Network for Organ Sharing; ISHLT, International Society for Heart and Lung Transplantation; REMATCH, Randomized Evaluation of Mechanical Assistance for the Treatment of Congestive Heart Failure; ESSENTIAL, Studies of Oral Enoximone Therapy in Advanced Heart Failure (Trial); COPERNICUS, Carvedilol Prospective Randomized Cumulative Survival (Study Group); CONSENSUS; MERIT HF; MIRACLE; US Carvedilol; CIBIS; RALES; VEHEFT; BEST; MADIT; DEFINITE; SOLVD Rx; SCD CHF. (From Cadeiras M, Von Beyern MP, Deng MC. Cardiac transplantation. Any role left? Heart Fail Clin. 2007;3:321-48. Reprinted with permission from Elsevier.)

(in the range of 3-4 L/min) are effective in relieving symptoms and reversing both the humeral and cytokine changes of heart failure. The new rotary blood pumps are considerably more patient friendly with lower complication rates. The surgery and postoperative care are less intimidating, and mechanical reliability is already established for a number of devices. ${ }^{10-12}$ As such, the rotary LVADs provide an unrestricted "off the shelf" solution to relieve symptoms and improve quality of life in those without access to transplantation.

Lifetime circulatory support has the potential to supercede transplantation by a factor of 20:1. A recent Society of Thoracic Surgeons/Food and Drug Administration Think Tank (Washington DC, September 2011) predicted the need for 40,000 LVADs annually in the United States, although at current costs this could account for half of the national heart failure budget ( $\$ 35$ billion). Because the devices all cost the same as a Porsche automobile, "intention to treat" with an implantable rotary LVAD should be on a long-term basis. Artificial differentiation between "bridge to transplant" or "destination therapy" groups is no longer useful inasmuch as patients are switched from one strategy to another depending on clinical progress and evolving patient preference. ${ }^{8}$ Even so-called "fixed pulmonary vascular resistance" ( $\geq 7.5$ Wood units) has been shown to be reversible during LVAD unloading, allowing patients unacceptable for transplantation to receive a donor heart in time. $^{34}$

Although acute cardiogenic shock and chronic severe heart failure cohorts are fundamentally different, they overlap when chronic heart failure decompensates precipitously and the patient needs to be rescued. Lietz and Miller $^{35} \mathrm{dem}-$ onstrated the futility of long-term VAD deployment in shock/multiorgan failure patients. They retrospectively allocated 280 HeartMate XVE patients into low, medium, high, and very high risk preoperative cohorts that provided 1 -year mortalities of $19 \%, 38 \%, 72 \%$, and $89 \%$, respectively. In a more recent analysis of patients with rotary blood pumps from the INTERMACS database, Boyle and associates $^{36}$ showed a dramatic difference in 3-year survival

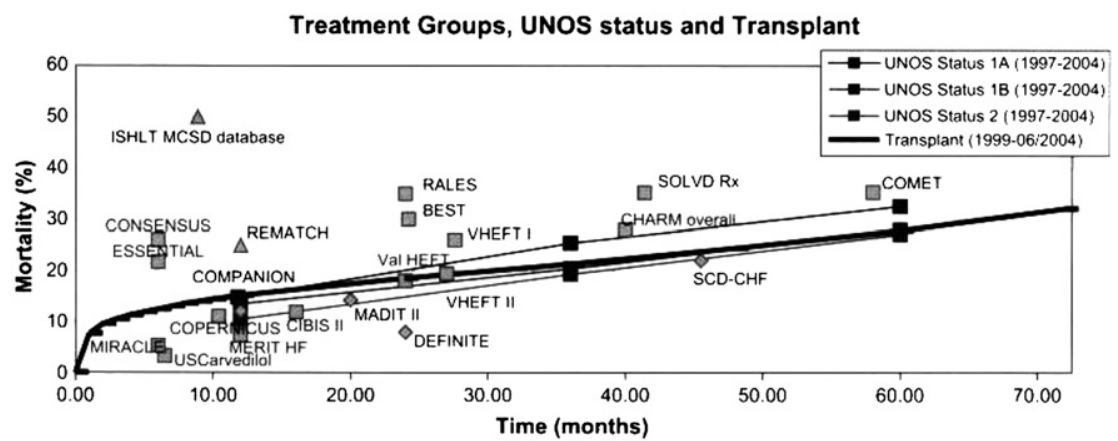

FIGURE 3. General comparative analysis of outcomes patients listed for heart transplantation as status 1A, 1B, and 2, patients undergoing orthotopic heart transplantation, mechanical circulatory support device implantation, and patients in the treatment groups reported by major clinical trials. For acronyms, see legend to Figure 2. (From Cadeiras M, Von Beyern MP, Deng MC. Cardiac transplantation. Any role left? Heart Fail Clin. 2007;3:321-48. Reprinted with permission from Elsevier.) 
between those operated on urgently in cardiogenic shock (INTERMACS I) versus severely symptomatic but electively implanted ambulatory patients in INTERMACS profiles 4 to $7(51.1 \%$ vs $95.8 \% ; P=.011)$. For inotropedependent patients in profiles 2 and 3 , the survival difference appeared substantial but failed to achieve statistical significance $(68.8 \%$ vs $95.8 \% ; P=.065)$. From an economic standpoint, the patients who had elective implantation left the hospital in 14 days versus 49 days for survivors of cardiogenic shock $(P<.001)$. These and other studies emphasize that carefully considered patient selection has an important impact on outcome and is the key to cost-effectiveness in a destination therapy program. ${ }^{37-39}$ Clearly, a less expensive short-term LVAD, extracorporeal membrane oxygenation, or a total artificial heart should be used for salvage. ${ }^{40}$ The implantable rotary LVADs are best deployed electively, preferably without conventional cardiopulmonary bypass, and perhaps with cell therapy in patients with ischemic cardiomyopathy. ${ }^{41,42}$ A more considered and selective approach greatly simplifies the perioperative management, optimizes outcome, and reduces costs. The LVAD then becomes "spend to save technology" by preventing numerous hospital admissions for palliation of heart failure.

Currently, the preferred candidates for lifetime support are those who are not yet hospitalized on inotropic therapy but are severely symptomatic and virtually housebound with poor survival prospects. ${ }^{43}$ Risk profiling based on data from the pulsatile LVAD (REMATCH) era does not translate directly to patients with a rotary blood pump inasmuch as virtually all prospective patients were then on intravenous inotropic support. ${ }^{44}$ A survey of patients with chronic ambulatory heart failure confirmed that they would consider an LVAD if they could walk less than 100 yards or were thought to have less than 12 months' projected survival. ${ }^{45}$ This provided the "one block or one year rule" as the trigger for referral for circulatory support. The latest INTERMACs data show a decrease in patients with cardiogenic shock taken directly for lifetime support but show an increase in comorbid risk factors associated with greater age and previous coronary bypass surgery. ${ }^{8}$

After REMATCH, further prospective randomized trials of LVAD versus continued medical therapy were deemed unnecessary for INTERMACS profile 1,2,3 patients. $^{3}$ They remain justified in the housebound, walking wounded, and advanced NYHA class III cohorts (INTERMACS 4-7) and in UNOS status II transplant candidates. Together with INTrePID and CUBS, REMATCH spelled the end for the pulsatile LVADs. ${ }^{46,47}$ These have not been used in the United States since January $2010{ }^{8}$ In contrast, 3 key elements account for the improvement in rotary blood pump outcomes. These are progressive improvements in bioengineering, revisions of patient selection, and refinement of perioperative management. Slaughter and associates ${ }^{48}$ showed the jump from pulsatile to continuous flow technology to be highly significant. Comparing the HeartMate XVE with HeartMate II in patients aged 26 to 81 years (median, 64 years) undergoing destination therapy, actuarial survival at 2 years was $24 \%$ versus $58 \%(P=.008)$. There were significant reductions in major adverse events (infection, renal failure, right ventricular failure) although the incidence of stroke was similar (17\% for HeartMate II, $14 \%$ for HeartMate XVE). The leading cause of death among patients with HeartMate II was hemorrhagic stroke in $9 \%$ versus $10 \%$ for HeartMate XVE. Embolic stroke rate for HeartMate II (6/100 patient-years) was similar to that experienced by patients with chronic heart failure and atrial fibrillation. Because the percutaneous driveline was smaller and less stiff, driveline infection rate was $50 \%$ of that experienced with the HeartMate XVE. ${ }^{48}$

In Europe, the Jarvik 2000 device (Jarvik Heart, Inc, New York, NY) has been used extensively with power delivery through a skull-mounted pedestal designed to minimize driveline infection ${ }^{49}$ (Figure 1). Based on cochlear implant hearing technology and with rigid fixation to the skull, there is no movement in relation to scalp skin. The scalp itself is highly vascular with little fat. Healing occurs rapidly and infection is rare. The blood pump is remote from the site of power delivery and all extracorporeal components (cables, controller, and batteries) exposed to wear and tear are exchangeable. The system effectively eliminates the sequence of pyogenic bacterial driveline infection superceded by fungal colonization after antibiotic treatment. ${ }^{50}$ Emphasizing the potential for this approach, the first patient to receive the system as a permanent solution (2000) survived for $71 / 2$ years with good quality of life (more than $10 \%$ of his overall life span). ${ }^{12}$ There were no device-related complications and he died of a noncardiac cause. In the current US Jarvik bridge to transplant trial with new cone bearings in the pump, 6-, 12-, and 24-month survivals are $91 \%, 87 \%$, and $87 \%$, respectively (unpublished data from Jarvik Heart, New York, NY).

In 2011, Strueber and coworkers ${ }^{10}$ reported a multicenter prospective clinical evaluation of the HeartWare Ventricular Assist System (HeartWare Inc, Framingham, Mass), which included 50 NYHA class IV transplant candidates. The mean duration of pump support was 348 days (range, 12-847 days) and there were no mechanical failures. Nine $(18 \%)$ patients died during support at a median duration of 94 days (range, 13-515 days). Survival of the patients who underwent transplantation, manifest left ventricular recovery, or were on ongoing support was $90 \%$ at 6 months, $85 \%$ at 1 year, and $79 \%$ at 2 years. All patients recovered from chronic heart failure with improvements in endorgan function, quality of life, and neurocognitive function. Embolic stroke occurred in only 2 of the 50 patients within the first 30 days. However, 4 pumps were replaced because of thrombus formation, 2 through bearing problems, and 
a seventh owing to complications of implantation (14\% overall).

In a single-center study of 55 patients who received the HeartMate II LVAD between 2005 and 2010, Adamson and coworkers ${ }^{51}$ compared outcomes between patients who were older $(n=30)$ or younger $(n=25)$ than 70 years of age. All patients were in NYHA class IV and not amenable to medical therapy. Kaplan-Meier survival for patients older than 70 years $(75 \%$ at 1 year and $70 \%$ at 2 years) was not statistically different from that of younger patients ( $72 \%$ at 1 year and $65 \%$ at 2 years; $P=.80$ ). The authors concluded that whereas younger patients wished to live longer, the older age group wanted to live better and were very appreciative of the improved quality of life.

To date, established right heart failure remains a contraindication to destination therapy although a fall in pulmonary artery pressure may improve the situation. ${ }^{34}$ Predictive guidelines are imperfect and total artificial hearts are not yet appropriate for widespread use in this context. ${ }^{8}$ Biventricular rotary blood pump support has been used in the bridge to transplant setting, but there are problems in balancing pulmonary versus systemic flow. Fit of the inflow cannula in the crescentic right ventricle is also problematic when pulmonary artery pressure falls and cavity size decreases. ${ }^{52}$

\section{THE WAY FORWARD}

With expansion of the evidence base, patterns of care are emerging. Transplantation is the restricted commodity and is predominantly directed toward young status I patients with acute or chronic heart failure to prolong life. In contrast, the implantable rotary pumps are increasingly deployed electively for refractory symptoms in non-transplant-eligible patients, those unlikely to receive a donor heart, and the elderly. ${ }^{38}$ Patient characteristics define suitability for each treatment (Table 1). Suggestions regarding the optimum candidate for transplant versus mechanical support are presented in Table 2. The differences indicate that the 2 approaches are complementary rather than competitive.

We have reached the stage whereby long-term LVAD therapy should be discussed with transplant candidates who face a prolonged wait for a donor heart (risking interim death) or be offered a marginal organ. Further refinements of the LVAD approach using adjuvant medical therapy or direct stem cell injection to improve myocardial contractility may eventually provide equivalence between transplant and LVAD. ${ }^{42,53}$ Why then were only 464 destination therapy LVADs implanted in the United States in 2010? First, there are perceived difficulties in identifying patients who are progressing toward an early death but are not yet dying. ${ }^{54}$ These are usually UNOS status II patients, many of whom would choose LVAD support for symptomatic relief irrespective of survival benefit. ${ }^{4}$ To allow the younger of these patients $(<70$ years $)$ to deteriorate to a cachectic state with multiorgan dysfunction
TABLE 1. Preferred patient characteristics with regard to suitability for cardiac transplantation or a rotary blood pump

\begin{tabular}{|c|c|c|}
\hline & Transplant & LVAD \\
\hline Age (y) & $<55$ & $<75$ \\
\hline NYHA functional class & IV & III/IV \\
\hline INTERMACS profile & $1-3$ & $3-6$ \\
\hline UNOS status & $\mathrm{I}$ & II \\
\hline Peak $\mathrm{Vo}_{2}\left(\mathrm{~mL} \cdot \mathrm{kg}^{-1} \cdot \mathrm{min}^{-1}\right)$ & $<12$ & $<12$ \\
\hline $\operatorname{LVEF}(\%)$ & $<25$ & $<25$ \\
\hline PVR (Wood units) & $<2.5$ & $<7.5$ \\
\hline $\mathrm{BMI} \geq 30 \mathrm{~kg} / \mathrm{m}^{2}$ & Contraindication & Acceptable \\
\hline Diabetes & Contraindication & Acceptable \\
\hline $\begin{array}{l}\text { Renal impairment } \\
\quad(\text { creatinine }>2.5 \mathrm{mg} / \mathrm{dL} \text { ) }\end{array}$ & Contraindication & $\begin{array}{l}\text { Acceptable } \\
\text { (not dialysis) }\end{array}$ \\
\hline $\begin{array}{l}\text { Right heart failure } \\
\qquad(\mathrm{CVP}>20 \mathrm{~mm} \mathrm{Hg})\end{array}$ & N/A & Contraindication \\
\hline TR/AR & N/A & Needs repair \\
\hline Intracardiac shunt & N/A & Needs repair \\
\hline Malignant dysrhythmia & N/A & Needs ablation \\
\hline $\begin{array}{l}\text { Hepatic dysfunction (INR }>2.5 \text {, } \\
\text { bilirubin }>5 \mathrm{mg} / \mathrm{dL})\end{array}$ & Acceptable* & Contraindication \\
\hline Treated malignancy & Contraindication & Acceptable \\
\hline Advanced vascular disease & Contraindication & Acceptable \\
\hline Severe lung disease & $\begin{array}{l}\text { Heart-lung } \\
\text { transplant }\end{array}$ & Contraindication \\
\hline Hematologic/bleeding issues & Case by case & Contraindication \\
\hline Previous cardiac surgery & Acceptable & Acceptable \\
\hline Psychosis/cognitive dysfunction & Case by case & Contraindication \\
\hline Family support & Not essential & Essential \\
\hline Proximity to center & Not essential & Essential \\
\hline
\end{tabular}

LVAD, Left ventricular assist device; NYHA, New York Heart Association; INTER$M A C S$, Interagency Registry for Mechanically Assisted Circulatory Support; $U N O S$, United Network for Organ Sharing; $V_{2}$, volume of oxygen use; $L V E F$, left ventricular ejection fraction; $P V R$, pulmonary vascular resistance; $B M I$, body mass index; $C V P$, central venous pressure; $T R / A R$, tricuspid regurgitation/aortic regurgitation; INR, international normalized ratio; N/A, not applicable. *Acceptable if due to right heart failure but not established cirrhosis or portal hypertension.

before considering an LVAD could now be considered neglectful. ${ }^{43}$ Second is many cardiologists' perception of contemporary mechanical circulatory support. Based on publications about first-generation LVADs, this is

TABLE 2. Ideal candidates from a prognostic and economic standpoint

- Cardiac transplant: Age $<50$ years, UNOS status I, INTERMACS 1-2 without metabolic risk factors (obesity, diabetes, hypertension) or peripheral vascular disease with recoverable renal and hepatic dysfunction and low pulmonary vascular resistance. Should receive a young donor heart with short ischemic time.

- Rotary blood pump: Age $<70$ years, UNOS status II, INTERMACS 3-6 without right heart failure, hepatic dysfunction, metabolic risk factors, dialysis-dependent renal failure or contraindication to anticoagulation. Should undergo an elective implant for symptomatic relief. Needs a supportive family or equivalent.

UNOS, United Network for Organ Sharing; INTERMACS, Interagency Registry for Mechanically Assisted Circulatory Support. 
characterized by device failure and debilitating complications. ${ }^{3}$ In the absence of well-powered prospective studies of long-term rotary blood pump use, it has been difficult to persuade the cardiologist or regulatory bodies of the benefits of this approach. Stevenson and colleagues ${ }^{54}$ suggest that current outcomes already justify extension of LVAD therapy to INTERMACS profiles 4,5 , and possibly 6 . (Eighty percent of LVADs are currently used for bridge to transplant in INTERMACS I and 2 patients.) Extrapolating from this, when mean LVAD survival exceeds 3 years, destination therapy could be contemplated before transplantation.

The decision to use an LVAD for symptomatic relief and potential prognostic benefit in profiles 4 to 6 remains controversial. The surgical risks are less but so is the net benefit. The current Randomized Evaluation of VAD Intervention before Inotropic Therapy (REVIVE-IT) study should help with this. Meanwhile, trials of medical therapy and cardiac resynchronization generally show survivals of $80 \%$ and $75 \%$ at 1 and 2 years, respectively. ${ }^{42}$ Although blood pumps provide better functional capacity and symptomatic relief, they should achieve equivalent survival if they are to affect this population. Significantly, Eckman and associates ${ }^{55}$ compared consecutive LVAD patients with INTERMACS 4 to 6 profiles with their preimplant predicted Seattle Heart Failure Model survival. One- and 2-year survivals were $85 \%$ and $80 \%$, respectively, providing an absolute $27 \%$ reduction in predicted mortality by 2 years.

The catch 22 of lifetime LVAD therapy is that long-term blood pumps are largely limited to transplant centers and overtly non-transplant-eligible patients who may be candidates are not referred to these hospitals. ${ }^{56}$ Many patients who are submitted for palliative care alone could gain symptomatic relief and several extra years of life with an appropriate blood pump. So far, this message has not reached the primary care physician. Given the potential demand as transplantation declines in some countries, lifetime LVAD therapy could reasonably be performed in tertiary centers that specialize in nontransplant heart failure surgery. ${ }^{57}$ This approach is already endorsed in the United States and regulatory guidelines are established. ${ }^{58}$ Devices are improving rapidly and can be made available in sufficient numbers to address heart failure epidemiology.

In end-stage renal failure, the options are a kidney transplant or mechanical blood filtration (dialysis). Few patients younger than 80 years are just left to die. We now have the direct analogy in heart failure. In my view, both the mystique and the prohibitive device costs must be removed from LVAD therapy. Even the terminology should change. ${ }^{59}$ This may involve movement away from the transplant setting and widespread introduction into conventional heart failure surgery programs alongside "myocardial regeneration therapy." ${ }^{, 2,60}$ Unabated developments in pump safety and simplicity will justify studies of LVAD versus resynchronization therapy in patients in NYHA class III/IV. Severe heart failure will then sit firmly in the surgical domain.

\section{References}

1. Roger VL, Go AS, Lloyd-Jones DM, Benjamin EJ, Berry JD, Borden WB, et al, American Heart Association Statistics Committee and Stroke Statistics Subcommittee. Heart disease and stroke statistics—2012 update: a report from the American Heart Association. Circulation. 2012;125:e2-220.

2. Lloyd-Jones D, Adams RJ, Brown TM, Carnethon M, Dai S, De Simone G, et al. Heart disease and stroke statistics-2010 update. A report from the American Heart Association. Circulation. 2010;121:948-54.

3. Rose EA, Gelijns AC, Moskowitz AJ, Heitjan DF, Stevenson LW, Dembitsky W, et al. Long term mechanical left ventricular assistance for end stage heart failure. N Engl J Med. 2001;345:1435-43.

4. Stewart GC, Brookes K, Pratibhu PP, Tsang SW, Semigran MJ, Smith CM, et al. Thresholds of physical activity and life expectancy for patients considering destination left ventricular assist devices. J Heart Lung Transplant. 2009;28:863-9.

5. McAlister FA, Ezekowitz J, Hooton N, Vendermeer B, Spooner C, Dryden DM, et al. Cardiac resynchronization therapy for patients with left ventricular systolic dysfunction. A systematic review. JAMA. 2007;297:2502-14.

6. Boyle AJ, Russel SD, John R, Chen L, Aaronson KD, Farrar DJ. Comparing improvements in functional capacity in NYHA Class IV patients between a continuous flow left ventricular assist device and cardiac resynchronization therapy. J Am Coll Cardiol. 2008;5(Suppl A):A69.

7. Deng MC, Ardehali A, Shemin R, Hickey A, MacLellan R, Fonarow G. Relative roles of heart transplantations and long term mechanical circulatory support in contemporary management of advanced heart failure-a critical appraisal ten years after REMATCH. Eur J Cardiothorac Surg. 2011;40:781-2.

8. Kirklin JK, Naftel DC, Kormos RL, Stevenson LW, Pagani FD, Miller MA, et al. The fourth INTERMACS Annual Report: 4000 implants and counting. J Heart Lung Transplant. 2012;31:117-26.

9. Lietz K, Long JW, Kfoury AG, Slaughter MS, Silver MA, Milano CA, et al. Outcomes of left ventricular assist device implantation as destination therapy in the post-REMATCH era: implications for patient selection. Circulation. 2007;116: 497-505.

10. Strueber M, O'Driscoll G, Jansz P, Khagani A, Levy WC, Weiselthaler GM. Multicenter evaluation of an intrapericardial left ventricular assist system. J Am Coll Cardiol. 2011;57:1375-82.

11. Pagani FD, Miller LW, Russell SD, Aaronson KD, John R, Boyle AJ, et al. Extended mechanical circulatory support with a continuous flow rotary left ventricular assist device. J Am Coll Cardiol. 2009;54:312-21.

12. Westaby S, Banning A, Neil D, Poole-Wilson P, Frazier OH. Optimism derived from 7.5 years of continuous flow circulatory support. J Thorac Cardiovasc Surg. 2010;139:e45-7.

13. Shah MR, Starling RC, Longacre LS, Mehra MR, National Heart Lung and Blood Institute Working Group. Heart transplantation research in the next decade. A goal to achieving evidence based outcomes. J Am Coll Cardiol. 2012;59:1263-9.

14. Hunt SA, Rider AK, Stinson EB, Griepp RD, Schroeder JS, Harrison DC, et al. Does cardiac transplantation prolong life and improve its quality? An updated report. Circulation. 1976;54(Suppl):III56-60.

15. Westaby S. Non transplant surgery for heart failure. Heart. 2000;83:603-10.

16. Taylor DO, Edwards LB, Boucek MM, Trulock EP, Waltz DA, Keck BM, et al. Registry of the International Society for Heart and Lung Transplantation: twentythird official adult heart transplantation report-2006. J Heart Lung Transplant. 2006;25:869-79.

17. Stehlik J, Edwards LB, Kucheryavaya AY, Aurora P, Christie JD, Kirk R, et al. The Registry of the International Society for Heart and Lung Transplantation: twenty-seventh official adult heart transplantation report-2010. J Heart Lung Transplant. 2010;29:1089-103.

18. Leitz K, Miller LW. Improved survival of patients with end stage heart failure listed for heart transplantation. J Am Coll Cardiol. 2007;50:1282-90.

19. Hunt SA. Taking heart—cardiac transplantation. N Engl J Med. 2006;355:231-5.

20. Deng MC, DeMeester JMJ, Smits JM, Heinecke J, Scheld HH, on behalf of the COCPIT study group. The effect of receiving a heart transplant: analysis of a national cohort entered onto waiting list, stratified by heart failure severity. $B M J$. 2000;321:540-5.

21. Shah NR, Rogers JD, Ewald GA, Pasque MK, Geltman EM, Bailey MS, et al. Survival of patients removed from the heart transplant waiting list. $J$ Thorac Cardiovasc Surg. 2004;127:1481-5. 
22. Muller J, Wallukat G, Weng Y, Dandel M, Ellinghaus P, Huetter J, et al. Predictive factors for weaning from a cardiac assist device. An analysis of clinical, gene expression and protein data. J Heart Lung Transplant. 2001;20:202-7.

23. Kirklin JK, McGiffin DC, Pinderski LJ, Tallaj J. Selection of patients and techniques of heart transplantation. Surg Clin North Am. 2004;84:257-87.

24. Deng MC. Orthotopic heart transplantation: highlights and limitations. Surg Clin North Am. 2004;84:179-99.

25. Kilic A, Weiss ES, George TJ, Arnaoutakis GJ, Yuh DD, Shah AS, et al. What predicts long term survival after heart transplantation? An analysis of 9,400 ten year survivors. Ann Thorac Surg. 2012;93:699-704.

26. Kilic A, Conte JV, Shah AS, Yuh DD. Orthotopic heart transplantation in patients with metabolic risk factors. Ann Thorac Surg. 2012;93:718-24.

27. Russo MJ, Hong KN, Davies RR, Chen JM, Mancini DM, Oz MC, et al. The effect of body mass index on survival following heart transplantation: do outcomes support consensus guidelines? Ann Thorac Surg. 2010;251:144-52.

28. Lietz K, John R, Burke EA, Ankersmit JH, McCue JD, Naka Y, et al. Pretransplant cachexia and morbid obesity are predictors of increased mortality after heart transplantation. Transplantation. 2001;72:277-83.

29. Cadeiras M, Von Beyern MP, Deng MC. Cardiac transplantation. Any role left? Heart Fail Clin. 2007;3:321-48.

30. Packer M, Coats AJS, Fowler MB, Katus HA, Krum H, Mohacsi P, et al, Carvedilol Prospective Randomized Cumulative Survival Study Group. Effect of carvedilol on survival in severe chronic heart failure. $N$ Engl J Med. 2001;344: 1651-8.

31. Bristow MR, Saxon LA, Boehmer J, Kruegar S, Kass DA, De Marco T, et al. Comparison of Medical Therapy, Pacing, and Defibrillation in Heart Failure (COMPANION) Investigators. Cardiac-resynchronization therapy with or without an implantable defibrillator in advanced chronic heart failure. $N$ Engl J Med. 2004;350:2140-50.

32. Lowes BD, Higginbotham M, Petrovich L, DeWood MA, Rahko PS, Dec GW, et al. Low dose enoximone improves exercise capacity in chronic heart failure. Enoximone Study Group. J Am Coll Cardiol. 2000;36:501-8.

33. Westaby S, Bertoni G, Cleland C, Nishinaka T, Frazier OH. Circulatory support with attenuated pulse pressure alters human aortic wall morphology. $J$ Thorac Cardiovasc Surg. 2007; 133:575-6.

34. Mikus E, Stepanenko A, Krabatsch T, Loforte A, Dandel M, Lehmkuhl HB, et al. Reversibility of fixed pulmonary hypertension in left ventricular assist support recipients. Eur J Cardiothorac Surg. 2011;40:971-7.

35. Lietz K, Miller LW. Destination therapy: current results and future promise. Semin Thorac Cardiovasc Surg. 2008;20:225-33.

36. Boyle AJ, Ascheim DD, Russo MJ, Kormos RL, John R, Naka Y, et al. Clinical outcomes for continuous flow left ventricular assist device patients stratified by pre-operative INTERMACS classification. J Heart Lung Transplant. 2011;30: $402-7$.

37. Wilson SR, Mudge GH, Stewart CG, Givert MM. Evaluation for a ventricular assist device. Selecting the appropriate candidate. Circulation. 2009;119: 2225-32.

38. Flint KM, Matlock DD, Lindenfeld J, Allen LA. Frailty and the selection of patients for destination therapy left ventricular assist device. Circ Heart Fail. 2012; 5:286-93.

39. Lund LH, Mathews J, Aaronson K. Patient selection for left ventricular assist devices. Eur J Heart Fail. 2010;12:434-43.

40. Westaby S, Anastasiadis K, Wieselthaler GM. Cardiogenic shock in ACS. Part 2: Role of mechanical circulatory support. Nat Rev Cardiol. 2012;9:195-208.

41. Anastasiadis K, Antonitsis P, Argiriadou H, Khayat A, Papakonstantinou C, Westaby $\mathrm{S}$, et al. Use of minimal extracorporeal circulation circuit for left ventricular assist device implantation. ASAIO J. 2011;57:547-9.
42. Anastasiadis K, Antonitsis P, Doumas K, Koliakos G, Argiriadou H, Vaitsopolou C, et al. Stem cells transplantation combined with long-term mechanical circulatory support enhances myocardial viability in end-stage ischemic cardiomyopathy. Int J Cardiol. 2012;155:e51-3.

43. Westaby S. Destination therapy. Time for real progress. Nat Clin Pract Cardiovasc Med. 2008;5:477-83.

44. Teuteberg JJ, Ewald GA, Adamson RM, Leitz K, Miller LW, Tatooles AJ, et al Risk assessment for continuous flow left ventricular assist devices: does the destination therapy risk score work? J Am Coll Cardiol. 2012;60:44-51.

45. Allen LA, Rogers JG, Warnica JW, Disalvo TG, Tasissa G, Binanay C, et al. High mortality without ESCAPE: the registry of heart failure patients receiving pulmonary artery catheters without randomization. J Card Fail. 2008;14:661-9.

46. Rogers JG, Butler J, Lansman SL, Gass A, Portner PM, Pasque MK, et al, INTrEPID Investigators. Chronic mechanical circulatory support for inotrope dependent heart failure patients who are not transplant candidates: results of the INTrEPID trial. J Am Coll Cardiol. 2007;50:741-7.

47. Pae WE, Connell JM, Adelowo A, Boehmer JP, Korfer R, El-Banayosy A, et al, Clinical Utility Baseline Study (CUBS) Group. Does total implantability reduce infection with the use of a left ventricular assist device? The LionHeart experience in Europe. J Heart Lung Transplant. 2007;26:219-29.

48. Slaughter MS, Rogers JG, Milano CA, Russell SD, Conte JV, Feldman D, et al Advanced heart failure treated with a continuous flow left ventricular assist device. N Engl J Med. 2009;361:2241-51.

49. Westaby S, Siegenthaler M, Beyersdorf F, Massetti M, Pepper J, Khayat A, et al Destination therapy with a rotary blood pump and novel power delivery. Eur J Cardiothorac Surg. 2010;37:350-6.

50. Westaby S, Jarvik R, Freeland A, Piggot D, Robson D, Saito S, et al. Postauricular percutaneous power delivery for permanent mechanical circulatory support. J Thorac Cardiovasc Surg. 2002;123:977-83.

51. Adamson RM, Stahovich M, Chillcott S, Baradarian S, Chammas J, Jaski B, et al Clinical strategies and outcomes in advanced heart failure patient older than 70 years of age receiving the HeartMate II left ventricular assist device. $J$ Am Coll Cardiol. 2011;57:2487-95.

52. Westaby S, Frazier OH. Long term biventricular support with rotary blood pumps. Prospects and pitfalls. Eur J Cardiothorac Surg. 2012;42:203-8.

53. Ibrahim M, Rao C, Athanasiou T, Yacoub MH, Terracciano CM. Mechanical unloading and cell therapy have a synergistic role in the recovery and regeneration of the failing heart. Eur J Cardiothorac Surg. 2012;42:312-8.

54. Stevenson LW, Pagani FD, Young JB, Jessup M, Miller L, Kormos RL, et al INTERMACS profiles of advanced heart failure: the current picture. $J$ Heart Lung Transplant. 2009;28:535-41.

55. Eckman P, Rosenbaum A, Vongooru H, Basraon J, John R, Levy W. Survival of INTERMACS profile 4-6 patients after left ventricular assist device implant is improved compared to Seattle Heart Failure Model estimated survival. J Card Fail. 2011;17:S38-9.

56. Westaby S. Lifetime circulatory support must not be limited to transplant centers. Heart Fail Clin. 2007;3:369-76.

57. MacGowan GA, Parry G, Schueler S, Hasan A. The decline in heart transplantation in the UK. BMJ. 2011;342:d2483. http://dx.doi.org/10.1136/bmj.d2483.

58. Deng MC, Young JB, Stevenson LW, Oz MC, Rose EA, Hunt SA, et al. Destination mechanical circulatory support: proposal for clinical standards. J Heart Lung Transplant. 2003;22:365-9.

59. Moazami N, Feldman D. Rethinking the terminology of mechanical circulatory support. J Thorac Cardiovasc Surg. 2012;144:2-3.

60. Perin EC, Dohmann HE, Borojevic R, Silva SA, Sousa AL, Mesquita CT, et al. Transendocardial autologous bone marrow cell transplantation for severe chronic ischemic heart failure. Circulation. 2003;107:2294-302. 